\title{
ON A NONLINEAR PROBLEM OF THE BREAKING WATER WAVES
}

\author{
M. Kirane ${ }^{1}$, B.T. Torebek ${ }^{2,3}$
}

${ }^{1}$ Université de La Rochelle, La Rochelle, France

${ }^{2}$ Al-Farabi Kazakh National University, Almaty, Kazakhstan

${ }^{3}$ Institute of Mathematics and Mathematical Modeling, Almaty, Kazakhstan

E-mails: mkirane@univ-lr.fr, torebek@math.kz

The paper is devoted to the initial boundary value problem for the Korteweg-de VriesBenjamin-Bona-Mahony equation in a finite domain. This particular problem arises from the phenomenon of long wave with small amplitude in fluid. For certain initial-boundary problems for the Korteweg-de Vries-Benjamin-Bona-Mahony equation, we obtain the conditions of blowing-up of global and travelling wave solutions in finite time. The proof of the results is based on the nonlinear capacity method. In closing, we provide the exact and numerical examples.

Keywords: breaking waves; Korteweg-de Vries-Benjamin-Bona-Mahony equation; blow-up of solution; initial-boundary problems.

\section{Introduction}

\section{Breaking Waves}

In fluid dynamics, a breaking wave (see Fig. 1) is a wave whose amplitude reaches a critical level at which some process can suddenly start to occur that causes large amounts of wave energy to be transformed into turbulent kinetic energy. At this point, simple physical models that describe wave dynamics often become invalid, particularly those that assume linear behaviour.

\section{Breaking Waves}

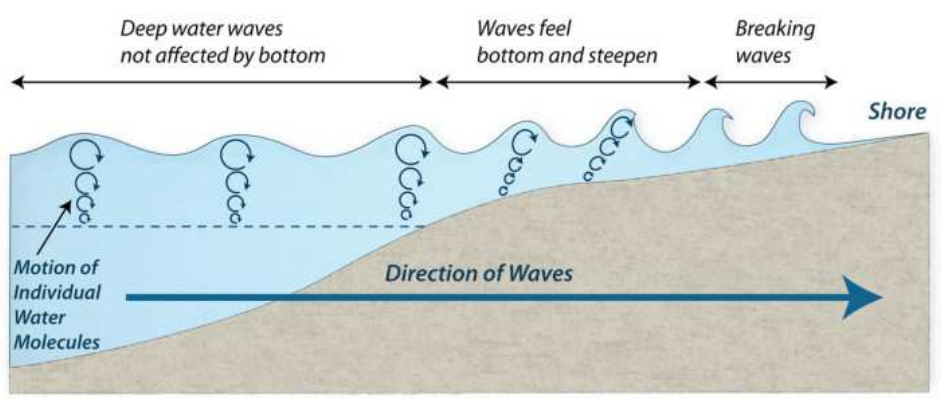

Fig. 1. Breaking waves

Breaking of water surface waves may occur anywhere that the amplitude is sufficient, including in mid-ocean. However, it is particularly common on beaches because wave heights are amplified in the region of shallower water (because the group velocity is lower there). There are four basic types of breaking water waves [1]. They are spilling, plunging, collapsing, and surging (see Fig. 2). 

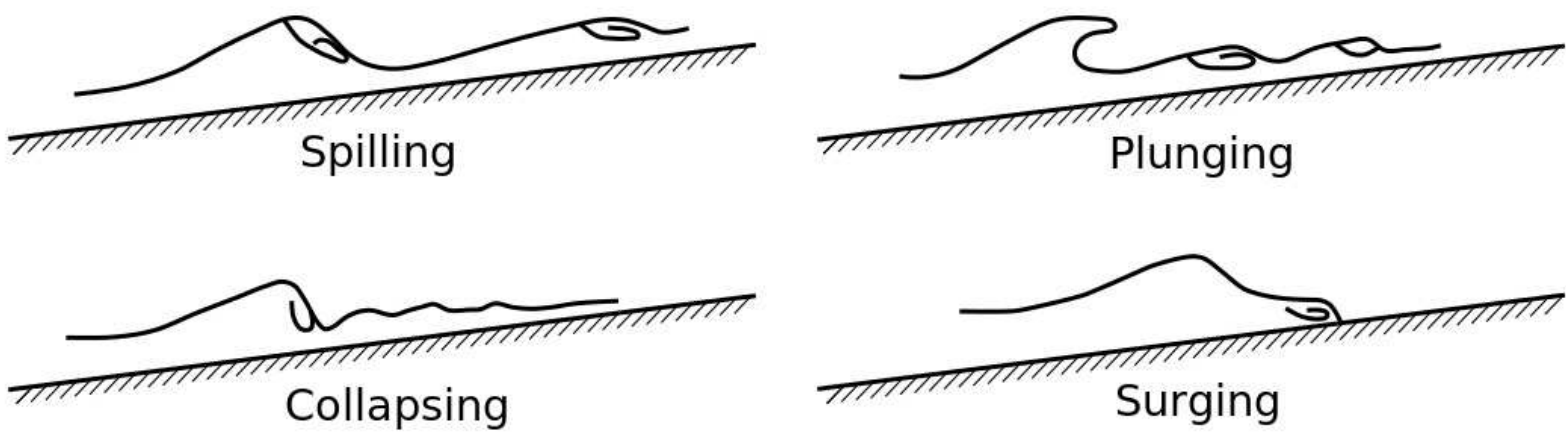

Fig. 2. Types of breaking water waves

\section{History of Problem}

The Korteweg-de Vries equation and the Benjamin-Bona-Mahony equation are two typical examples associated with the effects of dissipation, dispersion, nonlinearity and also provide a description of the propagation of waves with small amplitude in water or solution in other liquid medium. The Korteweg-de Vries equation is described as follows:

$$
u_{t}+u_{x x x}+u_{x}+u u_{x}=0 .
$$

The Benjamin-Bona-Mahony equation is an alternative to the Korteweg-de Vries equation [2] which is described as follows:

$$
u_{t}-u_{t x x}+u_{x}+u u_{x}=0 .
$$

Francius, Pelinovsky and Slunyaev introduced the wave dynamics of the following equation [3]:

$$
u_{t}-u_{t x x}+\alpha u_{x x x}+\beta u_{x}+u u_{x}=0,
$$

where $\alpha, \beta \in \mathbb{R}$. The equation (1) is so-called Korteweg-de Vries-Benjamin-Bona-Mahony equation.

\section{Statement of the Problem}

In this paper, we consider one of the mathematical problem of the breaking water waves, the Korteweg-de Vries-Benjamin-Bona-Mahony equation with initial conditions described as follows:

$$
\begin{gathered}
u_{t}-u_{t x x}+\alpha u_{x x x}+\beta u_{x}+u u_{x}=0, t>0, x \in(0, L), \\
u(x, 0)=u_{0}(x), x \in[0, L],
\end{gathered}
$$

where $\alpha, \beta \in \mathbb{R}$ and $u_{0}$ is given function.

The Korteweg-de Vries-Benjamin-Bona-Mahony equation has important application in different physical situations such as waves on shallow water, and processes in semiconductors with differential conductivity. In [5] Korpusov and Yushkov obtained sufficient conditions for the finite time blow-up of solutions of time and space initial problems for Korteweg-de Vries-Benjamin-Bona-Mahony type equation in the form

$$
u_{t}-u_{t x x}-u_{x x x}+u u_{x}=0 .
$$

They used the powerful method of nonlinear capacity, developed by S.I. Pohozhaev [10]. 
We also note that the blowing-up of solutions of the initial problems for the Kortewegde Vries and critical Korteweg-de Vries equations are investigated in [6-9,13-15]. Recently $\mathrm{Li}$ and Liu [4] studied the global and local (with respect to $t>0$ ) solvability of the problem (2), (3) with boundary conditions

$$
\begin{aligned}
& u(0, t)=h_{1}(t), \\
& u(L, t)=h_{2}(t), \\
& u_{x}(L, t)=h_{3}(t), t \geq 0 .
\end{aligned}
$$

This paper is devoted to singular solutions of the problem (2), (3), more precisely, to solutions that blow up in a finite time. The approach to the problem is based on the method of nonlinear capacity [10,11], more precisely, on the choice of test functions corresponding to initial and boundary conditions under consideration.

Here, we give a simplest case of the analysis of a "rough" blow-up, i.e., the case where the solution tends to infinity as $t>T$ on $[0, L]$ of values $x$, more exactly, when the integral

$$
\int_{0}^{L} u(t, x) \varphi(x) d x
$$

tends to infinity as $t>T$ for the given test function $\varphi$.

\section{Main Result}

We consider a test function $\varphi \in C^{3}([0, L])$ and monotonically nondecreasing:

$$
\varphi^{\prime}(x) \geq 0 \text { for } x \in[0, L]
$$

and let the function $\varphi$ satisfy the following properties:

$$
\left\{\begin{array}{l}
\theta_{1}:=\int_{0}^{L} \frac{\left(\alpha \varphi^{\prime \prime \prime}+\beta \varphi^{\prime}\right)^{2}}{\varphi^{\prime}} d x<\infty \\
\theta_{2}:=\int_{0}^{L} \frac{\left(\varphi-\varphi^{\prime \prime}\right)^{2}}{\varphi^{\prime}} d x<\infty .
\end{array}\right.
$$

Suppose the classical solution $u(x, t) \in C_{t, x}^{1,3}((0, L) \times(0, T))$.

Multiply the Korteweg-de Vries-Benjamin-Bona-Mahony equation (2) by a test function $\varphi$ we have

$$
\begin{aligned}
\frac{\partial}{\partial t} \int_{0}^{L}\left(u(x, t)-u_{x x}(x, t)\right) \varphi(x) d x= & -\alpha \int_{0}^{L} u_{x x x}(x, t) \varphi(x) d x- \\
& -\beta \int_{0}^{L} u_{x}(x, t) \varphi(x) d x-\int_{0}^{L} u_{x}(x, t) u(x, t) \varphi(x) d x .
\end{aligned}
$$

Integrating by parts the last equation we obtain 


$$
\begin{aligned}
\frac{d}{d t} \int_{0}^{L} u(x, t)\left(\varphi(x)-\varphi^{\prime \prime}(x)\right) d x & =\alpha \int_{0}^{L} u(x, t) \varphi^{\prime \prime \prime}(x) d x+\beta \int_{0}^{L} u(x, t) \varphi^{\prime}(x) d x+ \\
& +\frac{1}{2} \int_{0}^{L} u^{2}(x, t) \varphi^{\prime}(x) d x+\left.\mathcal{B}(u(x, t), \varphi(x))\right|_{x=0} ^{x=L},
\end{aligned}
$$

where

$$
\begin{aligned}
\mathcal{B}(u(x, t), \varphi(x)) & =u_{t x}(x, t) \varphi(x)-u_{t}(x, t) \varphi^{\prime}(x)-\alpha u_{x x}(x, t) \varphi(x)+\alpha u_{x}(x, t) \varphi^{\prime}(x)- \\
& -\alpha u(x, t) \varphi^{\prime \prime}(x)-\beta u(x, t) \varphi(x)-\frac{1}{2} u^{2}(x, t) \varphi(x) .
\end{aligned}
$$

Then, using properties (4), we find

$$
\begin{aligned}
\int_{0}^{L}(2 u(x, t) & \left.\left(\alpha \varphi^{\prime \prime \prime}(x)+\beta \varphi^{\prime}(x)\right)+u^{2}(x, t) \varphi^{\prime}(x)\right) d x= \\
& =\int_{0}^{L}\left(u(x, t)+\frac{\alpha \varphi^{\prime \prime \prime}(x)+\beta \varphi^{\prime}(x)}{\varphi^{\prime}(x)}\right)^{2} \varphi^{\prime}(x) d x-\int_{0}^{L} \frac{\left(\alpha \varphi^{\prime \prime \prime}(x)+\beta \varphi^{\prime}(x)\right)^{2}}{\varphi^{\prime}(x)} d x .
\end{aligned}
$$

We denote by $w(x, t)$ the following function

$$
w(x, t)=u(x, t)+\frac{\alpha \varphi^{\prime \prime \prime}(x)+\beta \varphi^{\prime}(x)}{\varphi^{\prime}(x)} .
$$

Let

$$
F(t)=\int_{0}^{L} w(x, t)\left(\varphi(x)-\varphi^{\prime \prime}(x)\right) d x .
$$

By using the Hölder inequality for $F(t)$, we obtain the following estimate

$$
\left(\int_{0}^{L} w(x, t)\left(\varphi(x)-\varphi^{\prime \prime}(x)\right) d x\right)^{2} \leq \int_{0}^{L} w^{2}(x, t) \varphi^{\prime}(x) d x \int_{0}^{L} \frac{\left(\varphi(x)-\varphi^{\prime \prime}(x)\right)^{2}}{\varphi^{\prime}(x)} d x .
$$

Therefore, using the properties of the test function (5) for the expression (6), we obtain the following first order differential inequality

$$
F^{\prime}(t) \geq \frac{\theta_{2}^{-1}}{2} F^{2}(t)+\Phi(t)-\frac{\theta_{1}}{2}
$$

with initial condition

$$
F(0)=\int_{0}^{L}\left(u_{0}(x)+\frac{\alpha \varphi^{\prime \prime \prime}(x)+\beta \varphi^{\prime}(x)}{\varphi^{\prime}(x)}\right) \varphi(x) d x,
$$

where $\Phi(t)=\mathcal{B}(u(L, t), \varphi(L))-\mathcal{B}(u(0, t), \varphi(0))$. Then the following results are true

Theorem 1. Let $u_{0}(x) \in L^{1}([0, L])$ and the solution $u \in C_{t, x}^{1,3}((0, L) \times(0, T))$ of the equation (2) be such that there exists a function $\varphi$ satisfying conditions (4), (5) such that

$$
\Phi(t) \geq \sigma, \text { for all } t>0
$$


where $\sigma$ is a some constant. Then

(A) if $\sigma>\theta_{2}$, then $F(t) \rightarrow+\infty$ for $t \rightarrow T_{1}^{*}$, where

$$
T_{1}^{*}=\frac{2 \sqrt{\alpha}}{\sqrt{\sigma-\theta_{2}}}\left(\frac{\pi}{2}-\arctan \frac{F(0)}{2 \sqrt{\theta_{1}\left(\sigma-\theta_{2}\right)}}\right) ;
$$

(B) if $\sigma=\theta_{2}$ and $F(0)>0$, then $F(t) \rightarrow+\infty$ for $t \rightarrow T_{2}^{*}$, where $T_{2}^{*}=\frac{4 \theta_{1}}{F(0)}$;

(C) if $\sigma<\theta_{2}$ and $F(0)>2 \sqrt{\theta_{1}\left(\theta_{2}-\sigma\right)}$, then $F(t) \rightarrow+\infty$ for $t \rightarrow T_{3}^{*}$, where

$$
T_{3}^{*}=\frac{\sqrt{\theta_{1}}}{\sqrt{\theta_{2}-\sigma}} \ln \frac{F(0)+2 \sqrt{\theta_{1}\left(\theta_{2}-\sigma\right)}}{F(0)-2 \sqrt{\theta_{1}\left(\theta_{2}-\sigma\right)}} .
$$

Applying the theory of ordinary differential inequalities, Theorem 1 can be proved.

\subsection{Examples}

Example 1. Note that the trial function method has great practical convenience. For example, if in problem (2), (3) on the interval $[0,1]$ are given boundary conditions

$$
\begin{aligned}
& u(0, t)=0, u(1, t)=0, \\
& u_{x x}(1, t)-u_{t x}(1, t)-5 u_{x}(1, t)=0, t \geq 0 .
\end{aligned}
$$

Then, if $\varphi(x)=x^{5}$ we obtain $\theta_{1}:=741, \theta_{2}:=\frac{359}{5}$ and $\Phi(t)=0$, for all $t>0$. Hence it follows from Theorem 1 that, under condition

$$
\int_{0}^{1} u_{0}(x) x^{5} d x>\frac{2 \sqrt{1330095}}{5}
$$

the solution of problem (2), (3) blows up in finite time.

Example 2. Let $\alpha=0$ in problem (2), (3) on the interval $[0,1]$ and let the solution of problem (2), (3) satisfy the boundary conditions

$$
\begin{aligned}
& u_{x}(0, t)=0, u_{x}(1, t)=0, \\
& u^{2}(1, t)+2 \beta u(1, t)=0, t \geq 0 .
\end{aligned}
$$

Then, if $\varphi(x)=x$ we obtain $\theta_{1}:=\beta^{2}, \theta_{2}:=\frac{1}{3}$ and $\Phi(t)=0$, for all $t>0$. Hence it follows from Theorem 1 that, under condition

$$
\int_{0}^{1} u_{0}(x) x d x>\frac{2 \sqrt{3} \beta}{3}
$$

the solution of problem (2), (3) blows up in finite time.

Example 3. Let in problem (2), (3) on the interval $[0, L]$ are given boundary conditions

$$
\begin{aligned}
& u(0, t)=0, u_{x}(0, t)=0 \\
& u_{x x}(0, t)+u_{x}(0, t)+u_{t}(L, t)=0, t \geq 0 .
\end{aligned}
$$


Then, taking a function $\varphi(x)=(x-L)$ we obtain $\theta_{1}:=L, \theta_{2}:=\frac{L^{3}}{3}$ and $\Phi(t)=$ 0 , for all $t>0$. Hence it follows from Theorem 1 that, under condition

$$
\int_{0}^{L} u_{0}(x)(x-L) d x>\frac{2 \sqrt{3} L^{2}}{3}
$$

the solution of problem (2), (3) blows up in finite time.

Example 4. Let $\beta=0$ in the problem (2), (3) with

$$
u_{0}(x)=\mathcal{A} x, \mathcal{A} \neq 0
$$

on the interval $[0,1]$. The solution of this problem is the function

$$
u(x, t)=\frac{x}{T^{*}-t}
$$

where $T^{*}=1 / \mathcal{A}$.

Thus, for $\mathcal{A}>0$ the solution of this problem becomes $+\infty$ as $t \rightarrow T^{*}$. On the other hand, for $\mathcal{A}<0$ there exists a global (for all $t>0$ ) smooth solution of problem (2), (3).

We built the graph of the solution for $\mathcal{A}=1 / 66$. As can be seen from Fig. 3, the solution of the problem (2), (3) with $\mathcal{A}=1 / 66$ has a discontinuity at $t=66$.
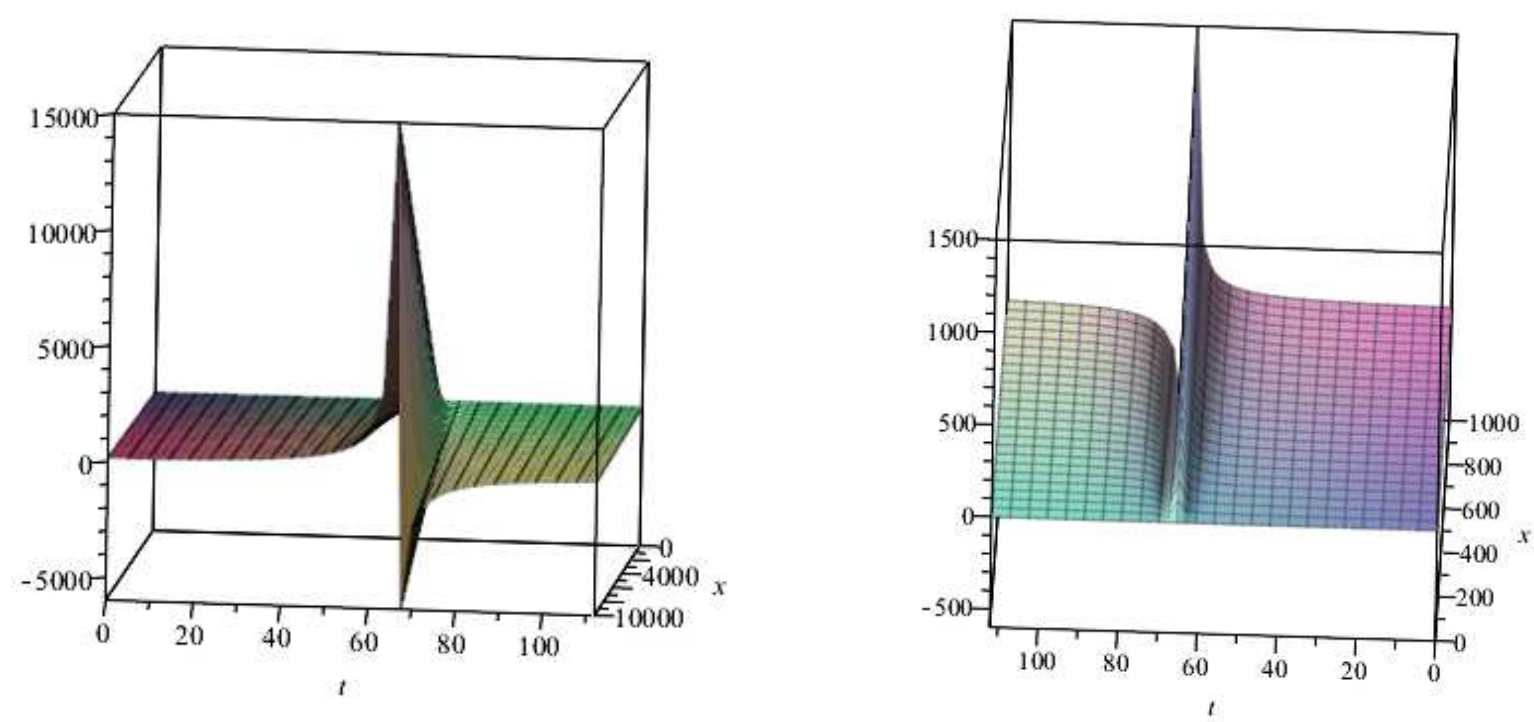

Fig. 3. Graphs of $u(x, t)$ for $\mathcal{A}=1 / 66$

\section{Singular Travelling Wave Solutions}

We consider the traveling wave type solutions of the Korteweg-de Vries-BenjaminBona-Mahony equation (1) with $\alpha=-1, \beta=1$ :

$$
u(x, t)=u(\xi),
$$

where $\xi=x-c t$ and $c$ is the wave velocity. Then $u(\xi)$ satisfies 


$$
(c-1) u^{\prime \prime \prime}-(c-1) u^{\prime}-u u^{\prime}=0 .
$$

Equation (8) admits the following integrals:

$$
(c-1) u^{\prime \prime}-(c-1) u-\frac{u^{2}}{2}-C_{0}=0 .
$$

Here $C_{0}$ is an arbitrary constant. A solution of (9) is a function $u \in L_{\text {loc }}^{2}(I), I \subset \mathbb{R}$ that satisfies the integral identity

$$
\int_{I} u^{2} \phi d \xi=2(c-1) \int_{I} u\left(\phi^{\prime \prime}-\phi\right) d \xi-2 C_{0} \int_{I} \phi d \xi, \quad \phi \in C_{0}^{2}(I) .
$$

\subsection{Nonexistence of Travelling Wave Solutions}

The following results are true

Theorem 2. The equation (8) with support $L \geq 2$, satisfying the inequality

$$
C_{0}>\frac{(c-1)^{2} b}{2 d L^{2}}
$$

does not admit a solution.

Proof. We multiply equation (9) by a nonnegative test function $\phi \in C_{0}^{2}(\mathbb{R})$ with compact support. Then after integration we obtain (10). Hence, by the Young inequality with parameter $a>0$, we find that

$$
\int_{I} u^{2} \phi d \xi \leq \frac{(c-1)}{a} \int_{I} u^{2} \phi d \xi+a(c-1) \int_{I} \frac{\left(\phi^{\prime \prime}-\phi\right)^{2}}{\phi} d \xi-2 C_{0} \int_{I} \phi d \xi .
$$

We now take the test function:

$$
\phi(\xi)=\phi_{0}(\eta), \eta=\frac{\xi}{L}
$$

where $L \geq 2$ is a free parameter and the function $0 \leq \phi \in C^{2}(I)$ such that

$$
\begin{gathered}
\phi_{0}(\eta)= \begin{cases}1, & \text { if }|\eta| \leq 1, \\
0, & \text { if }|\eta| \geq 2,\end{cases} \\
b=\int_{-2}^{2} \frac{\left|\phi_{0}^{\prime \prime}(\eta)-L^{2} \phi_{0}(\eta)\right|^{2}}{\phi_{0}(\eta)} d \eta<\infty .
\end{gathered}
$$

Then, if $a=c-1$ the inequality (12) implies

$$
(c-1)^{2} \frac{b}{L^{2}} \geq 2 C_{0} d, \quad d=\int_{-2}^{2} \phi_{0}(\eta) d \eta .
$$

From this it directly follows that if there exist $C_{0}$ such that the inequality (12) holds, then there is no such bounded traveling wave solution of equation (10). 


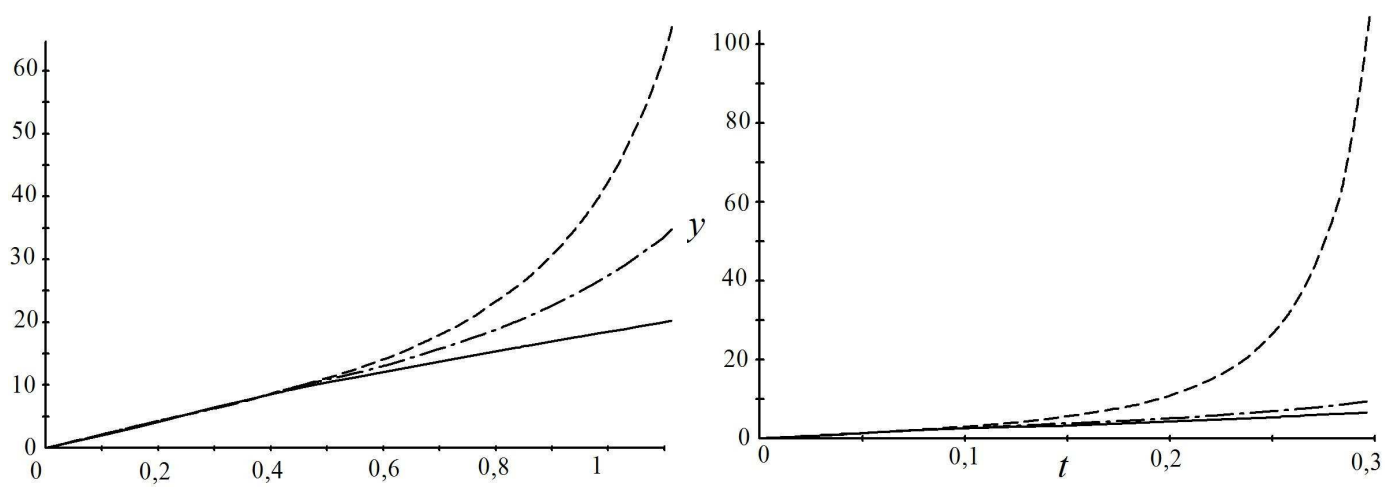

Fig. 4. Graphs of $u(\xi)$

\subsection{Numerical Examples}

In this subsection we consider some numerical examples for equation (9) with different viscosities. Suppose that we know some initial data for a traveling wave. Then it can be seen from Fig. 4, that the time for the blows-up of traveling waves increases if the wave velocity is decreasing.

\section{Conclusion}

The present paper is devoted to the initial problem for the Korteweg-de VriesBenjamin-Bona-Mahony equation in a finite interval. This particular problem arises from the phenomenon of long breaking waves with small amplitude in fluid. For certain initial-boundary problems for the Korteweg-de Vries-Benjamin-Bona-Mahony equation, we obtain conditions of blowing-up of local solutions in finite time. Proofs of the results are based on the nonlinear capacity method. We also proved the existence of the singular travelling wave solutions. Moreover, we provide some examples.

Acknowledgements. The second named author is financially supported by a grant from the Ministry of Science and Education of the Republic of Kazakhstan (Grant No. AP05131044).

\section{References}

1. Sarpkaya T., Isaacson M. Mechanics of Wave Forces on Offshore Structures. Van Nostrand Reinhold, 1981. DOI: 10.1115/1.3162189

2. Benjamin T.B., Bona J.L., Mahony J.J. Model Equations for Long Waves in Nonlinear Dispersive Systems. Philosophical Transactions of the Royal Society of London, 1972, vol. 272, pp. 47-78. DOI: $10.1098 /$ rsta.1972.0032

3. Francius M., Pelinovsky E.N., Slunyaev A.V. Wave Dynamics in Nonlinear Media with Two Dispersionless Limits for Long and Short Waves. Physics Letters, 2001, vol. 280, no. 2, pp. 53-57. DOI: 10.1016/S0375-9601(01)00042-1

4. Jie Li, Kangsheng Liu. Well-Posedness of Korteweg-de Vries-Benjamin-Bona-Mahony Equation on a Finite Domain. Journal of Mathematical Analysis and Applications, 2017, vol. 452, no. 1, pp. 611-633. DOI: 10.1016/j.jmaa.2017.02.038 
5. Korpusov M.O., Yushkov E.V. Local Solvability and Blow-Up for Benjamin-Bona-MahonyBurgers, Rosenau-Burgers and Korteweg-de Vries-Benjamin-Bona-Mahony Equations. Electronic Journal of Differential Equations, 2014, vol. 69, pp. 1-16.

6. Pokhozhaev S.I. On the Singular Solutions of the Korteweg-de Vries Equation. Mathematical Notes, 2010, vol. 88, no. 5, pp. 741-747. DOI: 10.1134/S0001434610110131

7. Pokhozhaev S.I. On the Nonexistence of Global Solutions for Some Initial-Boundary Value Problems for the Korteweg-de Vries Equation. Differential Equations, 2011, vol. 47, no. 4, pp. 488-493. DOI: 10.1134/S0012266111040045

8. Pokhozhaev S.I. On the Nonexistence of Global Solutions of the Cauchy Problem for the Korteweg-de Vries Equation. Functional Analysis and Its Applications, 2012, vol. 46, no. 4, pp. 279-286. DOI: $10.1007 / \mathrm{s} 10688-012-0035-\mathrm{z}$

9. Pokhozhaev S.I. Blow-Up of Smooth Solutions of the Korteweg-de Vries Equation. Nonlinear Analysis: Theory, Methods and Applications, 2012, vol. 75, no. 12, pp. 4688-4698. DOI: 10.1016/j.na.2011.08.021

10. Pokhozhaev S.I. Essentially Nonlinear Capacities Induced by Differential Operators. Proceedings of the USSR Academy of Sciences, 1997, vol. 357, no. 5, pp. 592-594.

11. Mitidieri E., Pokhozhaev S.I. A Priori Estimates and Blow-Up of Solutions of Nonlinear Partial Differential Equations and Inequalities. Proceedings of the Steklov Institute of Mathematics, 2001, vol. 234, pp. 1-362.

12. Mitidieri E., Pokhozhaev S.I. Towards a Unified Approach to Nonexistence of Solutions for a Class of Differential Inequalities. Milan Journal of Mathematics, 2004, vol. 72, pp. 129-162. DOI: $10.1007 / \mathrm{s} 00032-004-0032-7$

13. Martel Y., Merle F. Blow Up in Finite Time and Dynamics of Blow Up Solutions for the $L^{2}$-Critical Generalized KDV Equation. Journal of the American Mathematical Society, 2002, vol. 15, no. 3, pp. 617-664.

14. Martel Y., Merle F. Stability of Blow-Up Profile and Lower Bounds for Blow-Up Rate for the Critical Generalized KDV Equation. Annals of Mathematics, 2014, vol. 155, no. 1, pp. 235-280. DOI: $10.2307 / 3062156$

15. Martel Y., Merle F., Raphaël P. Blow Up for the Critical Generalized Korteweg-de Vries Equation. I: Dynamics Near the Solition. Acta Mathematica, 2014, vol. 212, no. 1, pp. 59-140. DOI: $10.1007 / \mathrm{s} 11511-014-0109-2$

Received October 9, 2018

УДК 517.95

DOI: $10.14529 / \mathrm{mmp} 190203$

\section{О НЕЛИНЕЙНОЙ ЗАДАЧЕ ЛОМАЮЩИХСЯ ВОДНЫХ ВОЛН}

\section{М. Киране ${ }^{1}$ Б.Т. Торебек $\boldsymbol{\kappa}^{2,3}$}

${ }^{1}$ Университет Ла Рошель, г. Ла Рошель, Франция

${ }^{2}$ Казахский национальный университет имени Аль-Фараби, г. Алматы, Казахстан

${ }^{3}$ Институт математики и математического моделирования, г. Алматы, Казахстан

Настоящая работа посвящена начальной краевой задаче для уравнения Кортевегаде Фриза - Бенджамина - Бона - Махони в конечной области. Эта задача возникает изза явления длинной волны с малой амплитудой в жидкости. Для некоторых начальнокраевых задач для уравнения Кортевега-де Фриза - Бенджамина - Бона - Махони мы получили условия разрушения глобальных решений и решений типа бегущей волны за 
конечное время. Доказательство результатов основано на методе нелинейной емкости. В заключение мы приводим точные и численные примеры.

Ключевые слова: разрушающие волны; уравнение Кортевега-де Фриза - Бенджамина - Бона - Махони; разрушение решение; начальные граничные задачи.

Мохтар Киране, доктор наук, профессор, Университет Ла Рошель (г. Ла Рошель, Франция), mkirane@univ-lr.fr.

Берикбол Тиллабайулы Торебек, $\mathrm{PhD}$, Казахский национальный университет имени аль-Фараби (г. Алматы, Казахстан); Институт математики и математического моделирования (г. Алматы, Казахстан), torebek@math.kz.

Поступила в редакиию 9 октября, 2018 г. 